\title{
MAPEAMENTO GEOMORFOLÓGICO DO BAIRRO HUMBERTO SALVADOR NA CIDADE DE PRESIDENTE PRUDENTE-SP
}

\author{
Daiane Barbosa Giroto ${ }^{1}$ \\ Bruna Dienifer de Souza Sampaio ${ }^{2}$ \\ Bruna Guldoni ${ }^{3}$
}

\begin{abstract}
RESUMO
Esse trabalho é um estudo sobre a geomorfologia do bairro Humberto Salvador, localizado ao norte da cidade de Presidente Prudente - SP. Teve por objetivo principal elaborar um mapa com as feições geomorfológicas do local. Foram realizados os procedimentos em laboratório de aerofotointerpretação, trabalho de campo no local estudado e revisão bibliográfica. A atividade permitiu observar como aconteceu a ocupação do solo e as intervenções do homem na paisagem. Também permitiu verificar in loco a não preocupação em causar o menor dano possível ao meioambiente, respeitando as condições naturais existentes antes de sua ocupação. Dessa maneira, foi possível verificar como as nascentes foram aterradas e os cursos d'águas canalizados, á ocupação de vertentes e a supressão da vegetação ciliar, o uso de fundos de vale para o descarte dos resíduos sólidos, remoção da mata nativa e o consequente surgimento de ravinas e erosões, empobrecendo o solo e ameaçando a população que ali se instalou. Assim, ficou evidenciado que o processo de expansão urbana é regido pelos interesses imobiliários, que compartimentaliza o uso do solo e cria enclaves discriminatórios das classes sociais, oferecendo as condições paisagísticas consideradas ótimas. Surgem, então, conjuntos residenciais em relevos colinosos suaves como um atrativo às classes mais favorecidas financeiramente, enquanto que relevos de declividades mais acentuados ou fundos de vales têm valores mais acessíveis às camadas sociais de menor poder aquisitivo.
\end{abstract}

PALAVRAS-CHAVES: Geomorfologia. Mapeamento. Humberto Salvador

\section{MAPPING THE GEOMORPHOLOGICAL IN NEIGHBORHOOD HUMBERTO SALVADOR IN SAGE PRESIDENTE PRUDENTE-SP}

\begin{abstract}
This work is a study of the geomorphology of Humberto Salvador neighborhood located north of the city of Presidente Prudente - SP. We had the main objective to draw up a map with the geomorphological features of the site. Procedures were performed in aerofotointerpretação lab, fieldwork in the study site and literature review. The activity allowed us to observe as happened to land use and Human interventions in the landscape. It also allowed spot verification of the concern not to cause the least possible damage to the environment, respecting the existing natural conditions before their occupation. In this way, we found as the springs were grounded and streams channeled waters shall occupation strands and the suppression of riparian vegetation, the use of valley bottoms

\footnotetext{
${ }^{1}$ Licenciada em Geografia, UNESP, Estudante Bacharel em Geografia. acolylle@hotmail.com.

${ }^{2}$ Licenciada em Geografia, UNESP, Estudante Bacharel em Geografia. bruna_jenny@hotmail.com.

${ }^{3}$ Licenciatura em Geografia, UNESP, Estudante. bruna.guldoni@hotmail.com
} 
for the disposal of solid waste, the native forest withdrawal and the consequent appearance of gullies and erosion, impoverishing the soil and threatening the population that settled there. Thus, it was evident that the urban expansion process is governed by real estate interests, which compartmentalizes land use and creates discriminatory enclaves of social classes, offering scenic conditions considered optimal. Arise then residential complexes in soft hillsing reliefs as attractive to the more affluent classes financially, while steeper slopes reliefs or valley bottoms have values more accessible to social strata with lower purchasing power.

KEYWORDS: Geomorphology. Mapping. Humberto Salvador

\section{MAPPING THE GEOMORFOLÓGICO EN BARRIO HUMBERTO SALVADOR EN PRESIDENTE PRUDENTE-SP}

RESUMEN: Este trabajo es un estudio de la geomorfología del barrio Humberto Salvador ubicada al norte de la ciudad de Presidente Prudente - SP. Teníamos el objetivo principal de elaborar un mapa con las características geomorfológicas del sitio. Los procedimientos se realizaron en aerofotointerpretação laboratorio, trabajo de campo en el sitio de estudio y revisión de la literatura. La actividad nos permitió observar como sucedió al uso del suelo y de intervenciones humanas en el paisaje. También permitió la verificación in situ de la preocupación de no causar el menor daño posible al medio ambiente, respetando las condiciones naturales existentes antes de su ocupación. De esta manera, encontramos que los muelles se quedaron en tierra y arroyos canalizados aguas deberá hebras de ocupación y la supresión de la vegetación de ribera, el uso de los fondos de los valles para la disposición de residuos sólidos, la eliminación del bosque nativo y la consiguiente aparición de cárcavas y erosión, empobrecimiento de los suelos y amenazando a la población que se asentó allí. Por lo tanto, era evidente que el proceso de expansión urbana se rige por intereses inmobiliarios, que compartimenta el uso del suelo y crea enclaves discriminatorias de las clases sociales, que ofrece condiciones escénicas considerado óptimo. Levántate complejos continuación residenciales en colinosos relieves suaves como atractivos a las clases más pudientes económicamente, mientras que las pendientes más pronunciadas relieves o fondo de los valles tienen valores más accesibles a los estratos sociales con menor poder adquisitivo.

PALABRAS-CLAVE: Geomorfología. Cartografía. Humberto Salvador

\section{INTRODUÇÃO}

A geomorfologia é a ciência que trata da configuração superficial da terra e tem por objetivo a análise, classificação, descrição das formas de relevo, buscando entender os processos passados e atuais. Desde os primórdios da civilização o homem tem se relacionado com o relevo de forma a dele se apropriar e explorá-lo, para satisfazer suas necessidades primárias. Ao longo do tempo, com o desenvolvimento alcançado pelas sociedades o relevo foi adquirindo grande importância em várias situações cotidianas, como para o planejamento urbano e regional, análise ambiental, entre outras. Ele então se tornou o alicerce sobre os quais se fixam as populações humanas, e onde desenvolvem suas atividades.

Com o decorrer do tempo foi atribuído maior peso ao homem sobre a sua interferência na modelagem do relevo, pois sua participação neste processo se intensificou. Dessa forma, este trabalho tem como foco o mapeamento das 
morfoesculturas do relevo, no bairro Humberto Salvador, localizado ao Norte da cidade de Presidente Prudente. As morfoestruturas são as formas da superfície terrestre produzidas pela interação de forças endógenas. As morfoesculturas são produzidas pelas forças exógenas. Como exemplo do resultado das forças endógenas, pode ser citado o Estado de São Paulo, onde há o cinturão orogenético do Atlântico, o Planalto Ocidental Paulista e o Planalto Centro Ocidental. Com a ação do tempo provocando o intemperismo das rochas, ao longo do tempo geológico formam as morfoesculturas como a Bacia Sedimentar do Paraná, Depressão Periférica Paulista, Planalto Residual de Marília.

Trabalhar o relevo é fundamental para compreender as mudanças paisagísticas e impactos causados pela apropriação do homem sobre o meio, para que assim possamos entender as várias realidades sociais, as formas de ocupação do solo, os problemas ambientais tanto nas áreas urbanas quanto nas áreas rurais. É importante conhecer as diversas maneiras de apropriação do solo e como a sociedade o explora e o expande, considerando que ás vezes são barradas por acidentes geográficos como cordilheiras ou montanhas que dificultam a expansão urbana.

Além disso, a maneira de apropriação do solo tem mudado as formas do relevo. Como exemplo, criam-se os depósitos tecnogênicos (entulhos ou lixos em fundos de vales). Portanto, devem-se mapear os compartimentos do relevo (as colinas: topos de colinas, vertentes; as planícies em berço ou em "V" encaixado), para respeitar as suas peculiaridades e dar um uso que agrida o meio ambiente com a menor intensidade possível.

Dessa forma, o relevo é o local onde se concretiza as diferenciações entre as classes sociais, principalmente, nesse padrão de sociedade capitalista por meio da especulação imobiliária. É comum ver construções de casas destinadas ás camadas pobres nas encostas dos morros e, consequentemente, os casos de calamidade quando há os deslizamentos do solo em que essa população pobre é afetada.

É comum a ocorrência dos casos de doenças respiratórias nas pessoas que vivem em ambientes úmidos e insalubres, recebendo pouca luz do sol e baixa ventilação. Da mesma forma, não é raro avistar mansões construídas em lugares inapropriados, mas que possibilitam a contemplação de belas paisagens. Como 
entender essa dinâmica e o processo da ocupação do território que está associada ao modelo de sociedade capitalista? Os geógrafos estão capacitados para articular essas questões e desvendar essa dinâmica, além de propor soluções visando á segurança das pessoas e assegurando a preservação do meio ambiente, que deve ser respeitado.

Diante dessas ponderações, esse estudo busca entender como a expansão urbana que originou o Conjunto Habitacional Jardim Humberto Salvador, localizado no município de Presidente Prudente - SP, apropriou-se e ocupou o solo modificando o relevo naquela área. Neste bairro há uma concentração de população de baixa renda, sendo considerada uma região de violência. A partir dessas características pretendemos rever o processo histórico de ocupação dessa área, e articular com os compartimentos de relevo existentes e os possíveis problemas que podem surgir causados pela estrutura morfológica onde está o bairro.

Também se faz presente no escopo deste trabalho á apresentação de mapas, feições geomorfológicas, fotos do ambiente acadêmico onde foram desenvolvidas as atividades envolvendo o uso do estereoscópio, aerofotos e o microscópio para percepção das planícies aluviais. Outra forma de representar o trabalho desenvolvido são as fotos produzidas pelo autores, em trabalho de campo elaborado no local estudado.

\section{OBJETIVOS}

O objetivo geral consistiu em elaborar o mapa geomorfológico com as compartimentações do relevo no bairro Humberto Salvador, no município de Presidente Prudente-SP. E os objetivos específicos foram: caracterizar os aspectos físicos (geologia, geomorfologia, pedologia), de Presidente Prudente; relacionar o relevo com a segregação socioespacial em Presidente Prudente; descrever as formas do relevo do bairro Humberto Salvador; conhecer a história e os diferentes usos de ocupação do solo nesse bairro; analisar pontos específicos desse bairro destacados no mapa geomorfológico.

\section{METODOLOGIA}

A metodológica consistiu em realização de trabalho de campo pela área urbana de Presidente Prudente, com destaque à área do Bairro Humberto Salvador, 
ampla revisão bibliográfica sobre a área de estudo. Com a utilização de fotografias aéreas (folhas $6,7,8$, do ano 1995) na escala 1: 25.000 e o aparelho de estereoscopia (Figura 1) e overlay (papel vegetal), foi realizado o trabalho de fotointerpretação, no Laboratório de Interpretação de Imagens do Departamento de Cartografia da FCT/UNESP, com a visualização ${ }^{4}$ em 3D (Figura 2) das nuanças do relevo e extração de suas principais feições de forma sequencial no overlay. Primeiramente, se deu a extração da feição das drenagens, depois, dos divisores de água, dos topos de colinas, das planícies aluviais, dos fundos de vale em berço ou em "V", das cabeceiras de drenagem em forma de anfiteatro, das morfologias das vertentes (côncava, convexa ou retilínea) e dos solos.

Figura 1: Estereoscópio e as duas fotografias aéreas

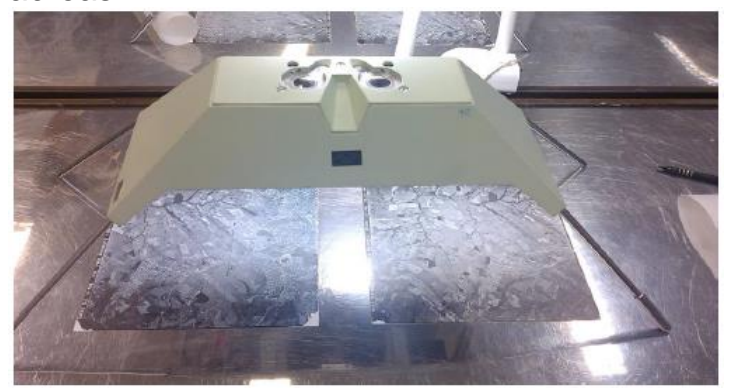

Figura 2: Uso do microscópio na estereoscopia

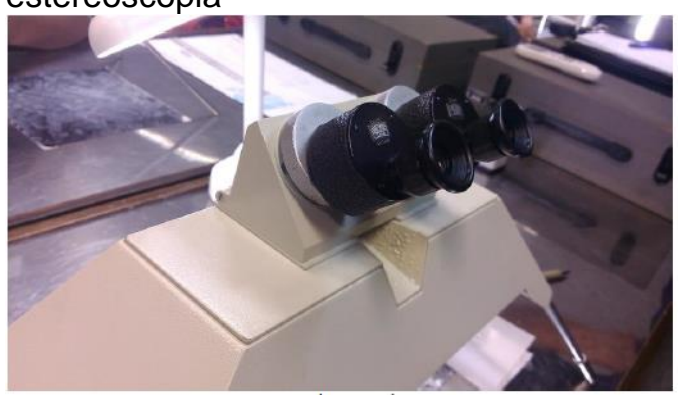

Fonte: Giroto, Sampaio \& Guldoni, 2015

Após o processo de reconhecimento e extração das feições do relevo, foi realizada a correção das distorções (da estereoscopia) através da justaposição com a base corrigida do município de Presidente Prudente - SP, obedecendo à rede de drenagem (Mapa 1). Diante disso, foi realizado o campo para verificação in loco, da realidade do relevo e possíveis correções finais.

\footnotetext{
${ }^{4} \mathrm{O}$ uso das lentes com $45^{\circ}$ propicia que as duas fotografias se fundam no cérebro, e o relevo seja visualizado em 3D.
} 
Mapa 1: Feição geomorfológica do bairro Humberto Salvador elaborada com o uso da fotogrametria e a devida correção das distorções

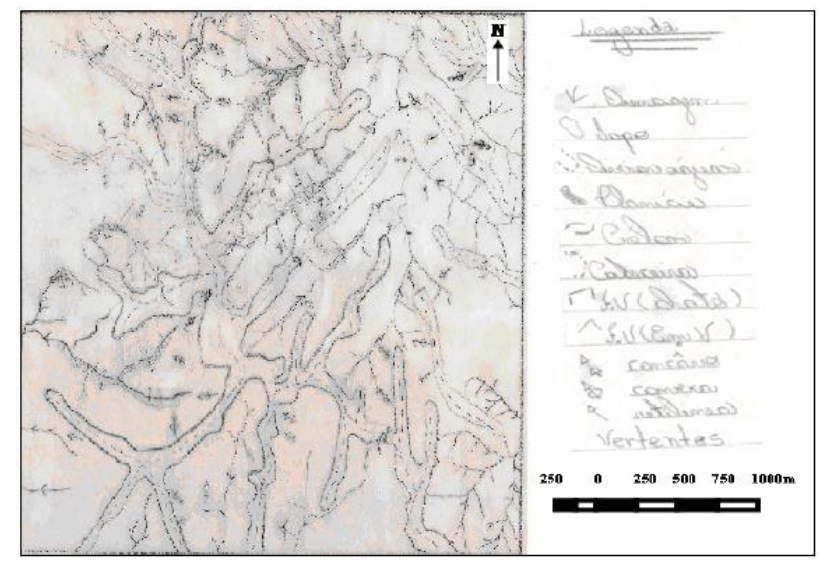

Fonte: Giroto, Sampaio \& Guldoni, 2015

Após as correções das feições adquiridas pela observação de campo, o outro passo da metodologia consistiu na utilização do software CorelDraw X5, na qual necessita de domínio técnico para realização desta etapa. No CorelDraw foi retirado as feições finais do relevo e dividindo-as em camadas para posteriormente "colorir" com base no mapa do relevo. E o resultado foi o Mapa Geomorfológico do Bairro Humberto Salvador (ver Mapa 2).

Mapa 2: Mapa Geomorfológico completo do Bairro Humberto Salvador, Presidente Prudente - SP

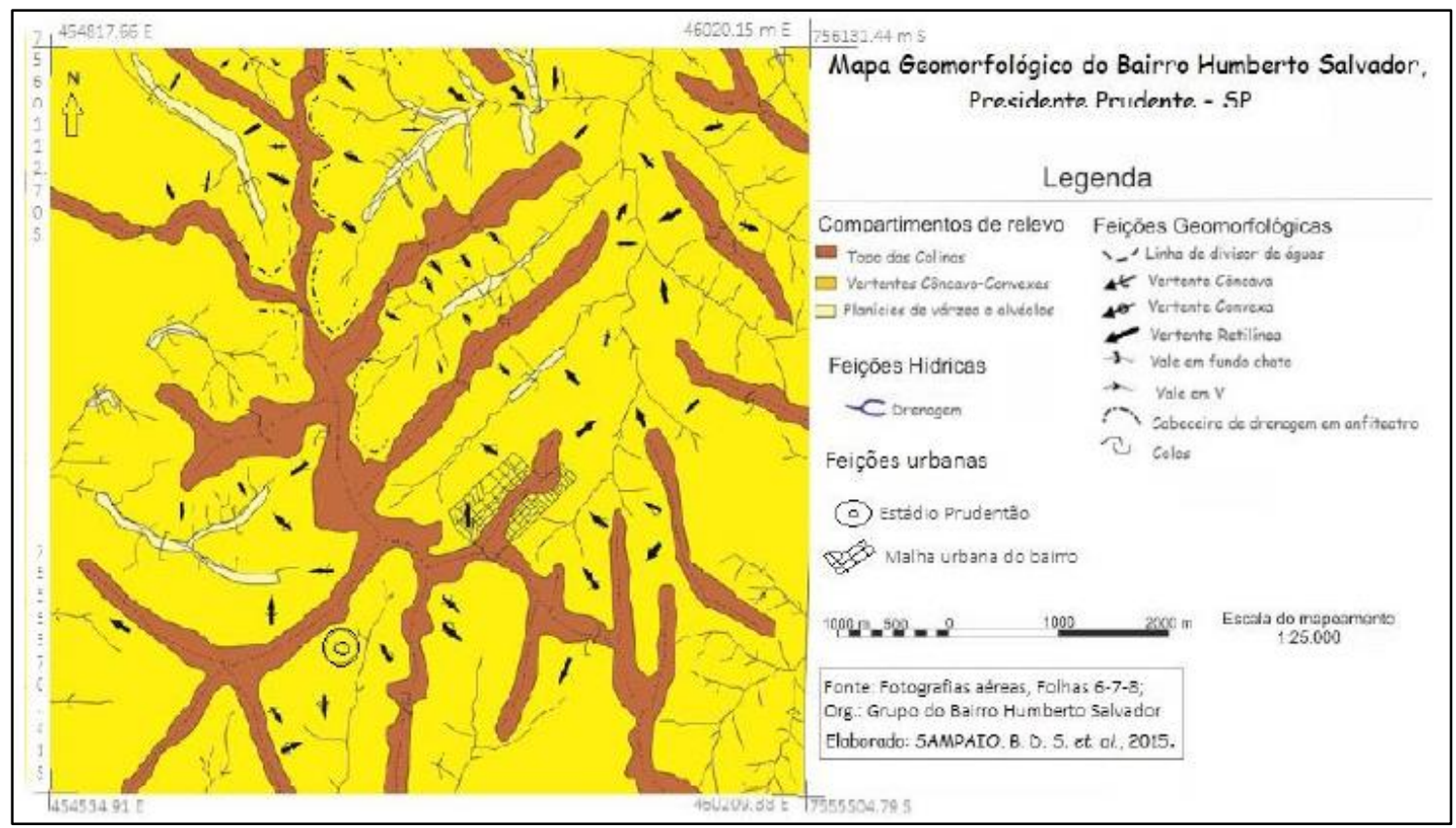

Fonte: Giroto, Sampaio \& Guldoni, 2015 


\section{Periódica Eletrânica \\ Fórum Ambiental}

da Alta Paulista
Volume 11, Número 05, 2015

Geotecnologias Aplicadas

à Análise Ambiental

Em relação à bibliografia, foi utilizado o modelo proposto pela escola Alemã comandada por Penck, sendo esta uma das vertentes que deram início a geomorfologia, com seu estudo na Geomorfologia Climática, onde o "relevo seria o resultado de uma sucessão de condições climáticas necessariamente diferentes do período atual" (NUNES, 2002, p. 24). Com isso se deu a análise e a compreensão das mudanças paisagísticas da área escolhida, pois, a partir da Escola Alemã sobre a compreensão da dinâmica da natureza (conceito de paisagem) foi que se originou a preocupação ambiental (NUNES, 2002). Atualmente, independente do paradigma das escolas, os estudos sobre a dinâmica da natureza perderam espaço para os estudos com as questões ambientais (na perspectiva socioambiental).

É importante entender a forma de ocupação do relevo, comandada pelos agentes econômicos e sociais, porque a ação desses agentes é um fator preponderante na construção de novas formas de relevos e paisagens geográficas (NUNES, 2002, p. 34). Essa é a perspectiva que apresentamos neste trabalho, direcionada a uma análise das alterações sobre a geomorfologia causada pela ação dos agentes sociais atuantes os quais, com suas intervenções socioambientais movidas por interesses de financeiros influenciam na (re)construção da paisagem.

Dentro dessa perspectiva foram trabalhados alguns conceitos para a análise da ocupação do relevo sendo eles: expansão urbana, uso e ocupação do solo, paisagem, intervenção antrópicas na paisagem. Estes conceitos foram melhores compreendidos através dos três níveis abordados por Ab'Saber (1969), compartimentação morfológica, levantamento da estrutura superficial e o estudo da fisiologia da paisagem, e de três níveis relacionados com a urbanização enfatizados por Nir (1963) in Lacerda (2005 apud JORGE, 2011), do qual são: o período préurbano, período de construção e o período urbano. Respectivamente, os três níveis abordados por Ab'Saber, fazem relação primeiramente aos diferentes níveis topográficos e características que apresentam o relevo, estando estes diretamente relacionadas ao processo de ocupação, onde a geomorfologia ajuda a definir os diferentes graus de risco que uma área possui, sendo esta apropriada ou não para uma área de ocupação, como também os impactos que são gerados ao relevo devido ao uso de tal espaço; o segundo nível, é representado pela fragilidade do terreno, buscando-se compreender o processo histórico da evolução da estrutura do relevo, através das oscilações climáticas, compreendendo assim a dinâmica 
comandada pelos elementos do clima com relação à base atual que o relevo apresenta; e o terceiro, compreende os processos morfodinâmicos atuais, do qual o homem esta apresente na análise como sujeito modificador. Neste nível, a presença humana tem relação com a aceleração dos processos morfogenéticos, causadas pela ocupação e transformações antropogênicas no relevo geográfico, moldando a paisagem natural. Já os níveis abordados por Nir, relacionam-se primeiramente ao período pré-urbano, onde existe alguma atividade de construção, mesmo que pequena, fazendo surgir efeitos negativos dessa intervenção como erosão acelerada, aumento de vazões, aumento da sedimentação nas drenagens e corpos d'água (apud JORGE, 2011, p. 127), o segundo período de construção, são áreas que encontram-se expostas aos agentes climáticos, ocorrendo a execução de cortes e aterros, construção do sistema viário, edificações e instalação da rede de drenagem das águas pluviais e elementos de infraestrutura urbano. No último estágio, o período urbano é marcado por uma nova topografia, como impermeabilização extensiva, drenagem total ou parcialmente artificial, com descarga fora da área urbana.

Diante desses níveis, definiremos nosso trabalho, buscando assim fazer relações aos níveis apresentados por Ab'Saber e os apresentados por Nir.

\section{RESULTADOS E DISCUSSÕES}

O conjunto habitacional Jardim Humberto Salvador fica localizado na zona norte de Presidente Prudente, ocupa os topos, as altas e médias vertentes de um dos afluentes do Córrego da Onça. Os topos estão configurados e totalmente ocupados, possuem morfologias suavemente onduladas, com colinas médias, que chegam a atingir altitudes entre 445 a 460 metros.

Nos topos estão situados os divisores de água entre as bacias dos Rios Santo Anastácio (oeste) e Mandaguari (leste). Neste compartimento predominam as colinas de formas suaves. "Este compartimento possui uma morfologia que favoreceu a ocupação, pois apenas alguns pontos do loteamento precisaram de obras de engenharia específicas para terrenos íngremes, como a terraplanagem, o corte de taludes, etc." (PEDRO e NUNES, 2009, p. 127). 
Em uma das ramificações do topo, identificou-se uma área em forma de anfiteatro com cabeceira de drenagem, completamente descaracterizada, onde foram construídos vários lotes e um campo de futebol.
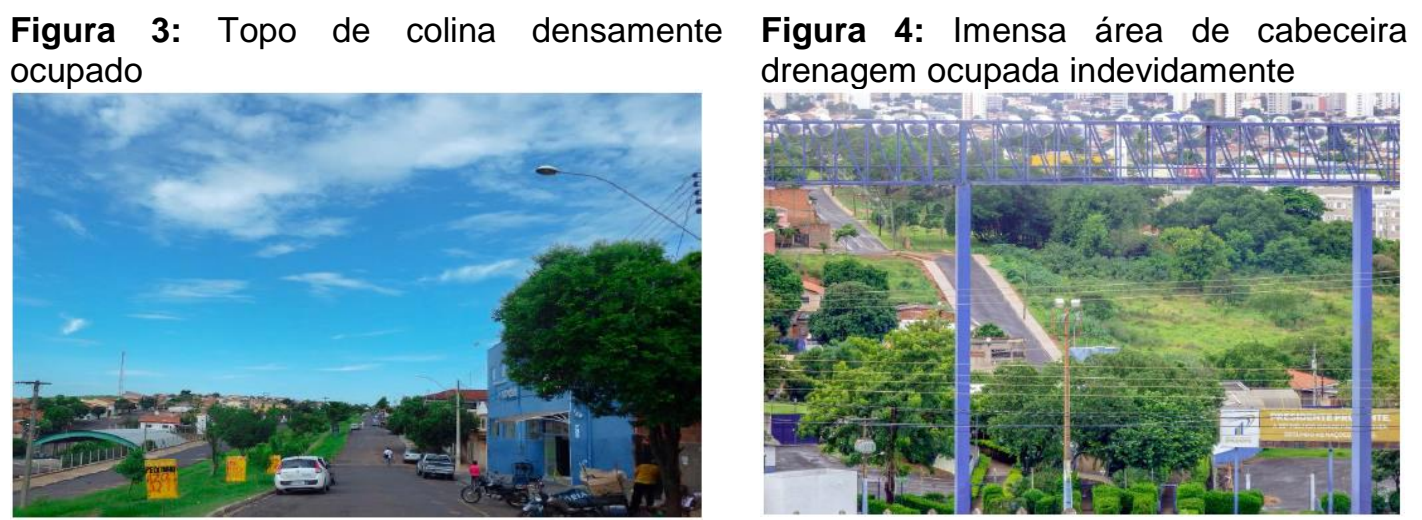

Fonte: Giroto, Sampaio \& Guldoni, 2015

Pedro (2008, p.105) afirma que a cabeceira de drenagem do "Conjunto Habitacional Jardim Humberto Salvador" teve uma transformação de origem antrópica, pois, com a instalação do loteamento o relevo foi esculturado, os canais de escoamentos e dinâmica do escoamento das águas pluviais foram alterados.

Segundo Pedro, nos locais de vales abertos do Conjunto Habitacional Jardim Humberto Salvador as declividades variam até $15 \%$, as altitudes dos fundos de vale do bairro variam entre 430 a $410 \mathrm{~m}$. Esses vales podem configurar-se em áreas de planícies. Atualmente, não há presença de cursos d'água no bairro, porém nas áreas adjacentes encontram-se alguns afluentes do Córrego da Onça.

Nunes e Pedro (2009, p.128) afirma que nas morfologias dos fundos de vale em V são encontradas as matas ciliares, e nas morfologias em berço têm-se os resquícios de vegetação de pequeno porte, com bancos de areia no curso d'água, é o local onde se encontram as planícies aluviais.

Em relação às vertentes do bairro, Pedro (2008, p.115) afirma que as vertentes possuem morfologias convexa (localizadas nas altitudes de 415 a $430 \mathrm{~m}$, com declives de $15 \%$ a $25 \%$, ocupadas por pastagem), côncava (com declives entre 15 a 30\%, nas altitudes de 410 a $445 \mathrm{~m}$ e estão ocupadas por residências, áreas de lazer e recreação e pastagem) e retilínea (próximo aos cursos d'água e canais de escoamento, ocupadas por pastagem com gado) e às vezes mistas, com altitudes 
que variam ente 435 a 410 metros e declividades de $15 \%$ até $30 \%$ que pode trazer problemas aos residentes.

Podemos visualizar que o Bairro Humberto Salvador, se encontra sobre uma área de topo de colina, do qual o planejamento do bairro começa a descer as vertentes, em direção ao fundo de vale que, hoje, se encontra cercado, mas assoreado e no passado serviu de "lixão".

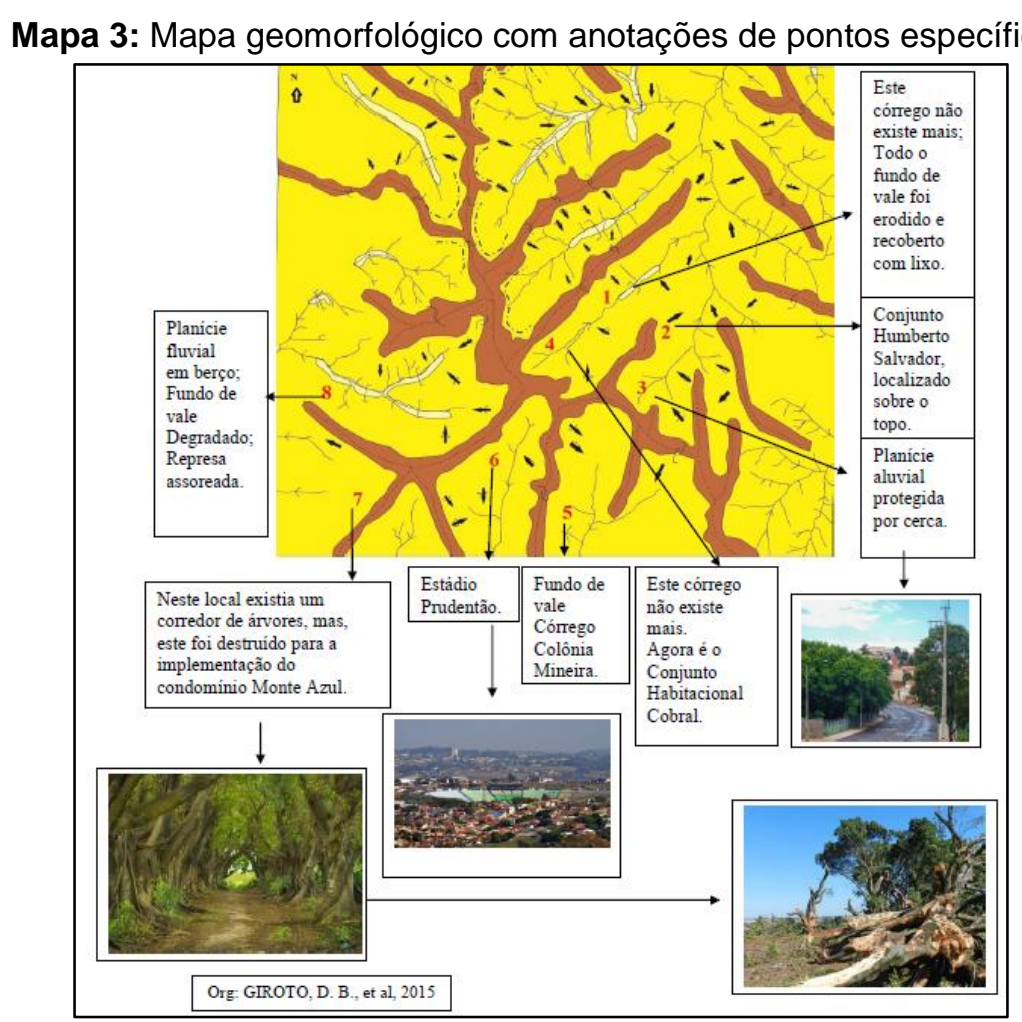

Fonte: Giroto, Sampaio \& Guldoni, 2015

Com base no mapa (Mapa 3), observa-se as mudanças e desequilíbrios/impactos ocorridos ao meio natural, devido ao processo de especulação imobiliária e falta de planejamento geomorfológico urbano. Diante disso, segue os pontos que se destacaram pelo processo acelerado e desordenado de ocupação ocasionados pelo homem.

- Ponto 1: foi visto que o córrego que antes existia, hoje já não mais se encontra, estando este assoreado, possuindo uma pequena mata ao redor, mas que ficou visível em campo a degradação do solo, por meio da erosão e dos depósitos tecnogênicos que ali foram e são depositados pela população, contribuindo ainda mais para a agressão ao meio ambiente; 
- Ponto 2: O Conjunto Habitacional Jardim Humberto Salvador, se encontra localizado sobre uma área de topo, do qual a expansão do bairro começa a descer as vertentes, como evidenciado no Mapa 03. A consolidação desse bairro se deu da mesma maneira que todos os outros da cidade de Presidente Prudente, começando primeiramente pela retirada da cobertura vegetal. Toda a sua construção por mais planejamento que tenha ocorrido, não levou em consideração os impactos ao meio ambiente. Tampouco as suas formas construídas irão reagir positivamente aos eventos extremos climáticos que ocorrem, por exemplo, chuvas torrenciais que tem como consequência as enchentes. Este problema sério que acontece dentro deste bairro, afeta diretamente uma escola construída na base de uma colina. Dessa forma, a água pluvial que escoa do topo da vertente vai em direção a ela, alagandoa.

- Ponto 3: Este ponto foi muito interessante, pois em meio a toda a devastação provocada pela urbanização, temos aqui uma planície aluvial cuja mata está protegida por cerca, com o objetivo de preservar o pouco que resta de natural a esta localização. Porém, a vegetação que surgiu espontaneamente é motivo de discórdia entre o Poder Público e os ambientalistas, que não concordam na sua manutenção alegando que se trata de vegetação exótica. Eles desejam a remoção da mesma, e que seja replantada a vegetação nativa.

- Ponto 4: O córrego localizado em frente à última rua do Humberto Salvador, como foi mencionado no Ponto 1 , já não existe, evidenciamos aqui outro processo de especulação imobiliária promovido pelo capital, direcionado à classe baixa e sem preocupação nenhuma com a preservação do meio ambiente, ou respeito aos atributos do relevo. A construção do conjunto Cobral, provocou tamanho deslocamento de solo, que assoreou um fundo de vale próximo, fazendo desaparecer o riacho e impermeabilizando o solo.

- Ponto 5: Com relação ao fundo de Vale do Colônia Mineira, retratamos aqui mais um impacto da urbanização, sendo este a impermeabilização do solo, fazendo com que a água não infiltre no solo. Dessa forma, ela escoa pelas ruas do bairro Vila Geni, principalmente, causando assim enchentes e fortes enxurradas que acabam por invadir as casas dos moradores desta região. Um segundo impacto, é a canalização do rio que devido a um mau dimensionamento da vazão pluvial, os 
dutos usados na construção não suportam o volume de água, causando inundação nas áreas próximas a ele.

- Ponto 6: O estádio do Prudentão e toda a área urbana que se encontra ao redor dele está localizada sobre várias nascentes. Localizado sobre a alta vertente, a sua construção causou o assoreamento de várias nascentes, encontrando neste local o afloramento de arenito (rocha sedimentar).

- Ponto 7: Este ponto é motivo de muita polêmica que o acompanha desde o início. A área onde está sendo implantado o Condomínio Monte Azul era, anteriormente, um grande corredor de árvores - as imagens estão expostas no mapa 03, e chegaram até a ganhar o Concurso Cultural Sua Foto, cujas imagens foram publicadas na Revista de renome National Geographic Brasil (https://plus.google.com/115767377634392686069/posts/4YNsYcCEYRf), na edição de abril de 2014. Meses após, este corredor de árvores foi derrubado para o início da implantação do Condomínio Monte Azul, visto que como sendo área particular a desculpa dos agentes econômicos foi a de que "este corredor de árvores não tinha importância nenhuma". Podemos observar aqui os conceitos abordados por Nir (1983), dos estágios da cidade, período pré-urbano, do qual o primeiro passo foi o corte das árvores, evidenciando assim o valor do relevo apenas para a urbanização e consolidação das edificações, não mais possuindo o valor ambiental que sua paisagem representava para o meio ambiente.

- Ponto 8: Esta é uma planície tecnogênica, com fundo de vale degradado, do qual o córrego que ali anteriormente existia, hoje está assoreado. Este é o típico modelo que encontramos praticamente em toda área de estudo, não só com enfoque ao bairro, mas também em suas adjacências, demonstrando assim a pouca preocupação da população e do Poder Público com o meio natural.

Pensando aqui nos três níveis abordados por Ab' Saber e por Nir, podemos observar que a ação antropogênica, ao eliminar a cobertura vegetal, aplainar o relevo, aterrar nascentes ou cursos d'água, e a construir uma nova paisagem, acaba por alterar de forma substancial as relações entre as forças de ação (processos morfogenéticos ou morfodinâmicos) e de reação superficial, tendo como consequência desequilíbrios e impactos ambientais, como assoreamento, voçorocas, perdas de solo. Assim, a ação do homem sobre o meio com base nessas consequências referidas aos três níveis mudam as características paisagísticas de 
todos os elementos que compõe o relevo, onde esta ação do homem o diferencia dos demais agentes e fatores geológicos, em sua ação sobre a natureza, que é a natureza antropomorfizada (Peloggia, 1998, apud JORGE 2011, p. 122 -123). modelo exemplificado por Nir (1983) deixa claro a importância da geomorfologia antrópica na ocupação do relevo, possibilitando pensar em uma utilização racional que preserve as formas naturais, o que pode somar valor ao solo urbano destinados às moradias, prevenindo que a urbanização acabe resultando em grandes impactos ambientais, quando é retirada a cobertura vegetal para a expansão urbana.

\section{CONSIDERAÇÕES FINAIS}

A preocupação da influência do homem sobre o meio ambiente começou a ser pensada na Academia, na década de 1950, com a obra de Ab'Saber - Sítio urbano de São Paulo. Porém, foi a partir de 1990 que seus estudos tiveram início, afim de, obter respostas para o crescente número de denúncias às agressões ambientais, gerando impactos que afetam toda a população e são causadas pelas ações antrópicas.

A cidade como menciona Bertalanffy (2008) é um organismo vivo, de sistema aberto e complexo, que possui características próprias (topografia, drenagem, geologia, uso do solo). Esta se reproduz, pois seu crescimento é inexorável, independente se for grandes, médias, ou pequenas cidades, elas se expandem e sempre da outro caráter à paisagem que agora é humanizada. Este é um processo que aumenta com o tempo, devido à necessidade de reprodução capitalista, sendo que ele elege os lugares aonde vai se reproduzir. Independe da classe a ser privilegiado com este crescimento, ele se reproduz tanto em locais para atender às classes economicamente inferiores, quanto às classes média ou alta. $\mathrm{O}$ espaço geográfico fica à disposição da reprodução do capital e suas escolhas.

Pensando no processo histórico de urbanização brasileira, esta é a característica que sempre esteve presente, ou seja, a retirada da cobertura vegetal para a expansão urbana. Então, dessa forma, fica difícil pensarmos em um processo que não reflita essa ordem, já que a sociedade se encontra acostumada a esse tipo de construção e consolidação urbana. Diante disso, para ser estabelecido um consenso seria necessário estudos, planejamento urbano das áreas de expansão na cidade, pensando até em uma política ambiental urbana posta em prática, visando 
menor impacto na geomorfologia urbana, buscando assim compreender os processos ambientais, seja na micro, meso ou macro escala de análise.

Portanto, é de fácil compreensão que os agentes econômicos e a necessidade de crescimento faça com que a cidade se expanda em diferentes direções do seu território, negligenciando os cuidados necessários tanto com o meio ambiente, quanto com a distribuição da população em locais adequados. Também fica para o segundo plano as condições de habitabilidade, se são apropriadas ou impróprias para a ocupação.

No entanto, as ocupações das áreas são muito seletivas, direcionadas as classes alta, média ou baixa, para os pontos distribuídos pelo relevo, segundo o seu valor de mercado. Esta expansão seletiva, que é o processo de urbanização, gera ao meio natural consequências sérias, principalmente ao relevo, sendo este totalmente alterado por essas ações.

O conjunto de ações que da origem a uma cidade beneficiando o habitante, ao mesmo tempo retorna a ele com as consequências de uma apropriação inadequada do espaço geográfico, não planejada. Dessa maneira, a ênfase aqui proposta visa denunciar os desequilíbrios e impactos ambientais ocorridos no bairro Humberto Salvador e as áreas próximas, no sentido de colaborar com os estudos que procuram apontar soluções que preservem os mesmos direitos básicos que as pessoas têm de usufruírem dos recursos naturais, independente da sua condição financeira.

\section{REFERÊNCIAS BIBLIOGRÁFICAS}

BERTALANFFY, L. V. Teoria Geral dos Sistemas: Fundamentos, desenvolvimento e aplicações. Petrópolis, RJ: Vozes, 2008

CASSETI, V. Elementos da geomorfologia. 1ª reimpressão. Goiânia: Ed UFG, 2001. 137p.

CASSETI, V. Geomorfologia. [S.1]: [2005]. Disponível em: <http://funape.org.br/geomorfologia/ > Acesso em: 23 mar 2015.

CHRISTOFOLETTI, A. Geomorfologia. São Paulo: Edgard Blücher, 2.ed, 1980. 188p.

GUERRA, A. J. T. Geomorfologia Urbana. Rio de Janeiro: Bertrand Brasil, 2011. 277p.

JORGE, M. do C. O. Geomorfologia Urbana: Conceitos, metodologias e teorias. In: Geomorfologia Urbana. Rio de Janeiro: Bertrand Brasil, 2011, p. 117-146.

NUNES; J. O. R.. Uma contribuição metodológica ao estudo da dinâmica da paisagem aplicada a escolha de áreas para construção de aterro sanitário em Presidente Prudente. Tese de doutorado, Unesp, Presidente Prudente, 2002. 211p. 
PEDRO, Leda Correia. Ambiente e apropriação dos compartimentos geomorfológicos do Conjunto Habitacional Jardim Humberto Salvador e Condomínio Fechado Damha. Presidente Prudente. 2008.

PEDRO, Leda Correia; NUNES, João Osvaldo Rodrigues. As ações antrópicas e as formações tecnogênicas: $\mathbf{O}$ caso do Jardim Humberto Salvador em Presidente Prudente-SP. Revista Geografar, v. 4, n. 2, 2009.

POPP, J. H. Geologia geral. 5.ed [reimpr.]. Rio de Janeiro: LTC, 2009. 376p.

RAMOS SILVA, João Vitor et al. Luta pela terra e as confluências geográficas entre cidade e campo em presidente prudente (sp-br). Cuadernos de Geografía: Revista Colombiana de Geografía; Vol. 23, n. 2 (2014); p.161-178. 